\title{
A educação ambiental como estratégia da Atenção Primária à Saúde
}

\author{
Environmental education as Primary Health Care strategy \\ Educación ambiental como estrategia de la Atención Primaria de Salud \\ Carlos Alexandre Rodrigues Pereira ${ }^{1 *}$, Juliana Valéria de Melo²$^{2}$, André Luis Teixeira Fernandes³
}

Palavras-chave:

Saúde Ambiental

Diagnóstico da Situação de Saúde em Grupos Específicos Prevenção de Doenças

\section{Resumo}

A Educação Ambiental não deve discutir somente o meio ambiente físico, mas também deve contextualizar a saúde local, destacando os cuidados com a prevenção de doenças e gestão dos fatores ambientais deletérios a saúde. Objetivo: Este trabalho teve como objetivo avaliar a eficácia da Educação Ambiental como estratégia da Atenção Primária à Saúde (APS) num pequeno núcleo urbano isolado no Município de Uberaba. Método: Foi realizado um diagnóstico socioambiental no período de agosto/2009 a janeiro/2010 por meio da aplicação de questionário semiestruturado de pesquisa quantitativa e qualitativa sobre saúde, meio ambiente e desenvolvimento social. Com base nos resultados do diagnóstico, foram elaboradas atividades que envolveram reuniões, palestras e eventos culturais que discutiam os problemas verificados no diagnóstico. A avaliação da eficácia das intervenções foi realizada por meio da verificação de ações comunitárias que surgiram após as atividades. Resultados: Obteve-se a mobilização da Secretaria Municipal de Saúde quanto à qualidade da água de consumo humano e a mobilização comunitária na organização e enfrentamento dos problemas vivenciados, relacionados à educação, assistência médica e representação comunitária. Essas ações não se devem exclusivamente ao trabalho de educação realizado, mas foram motivadas e incentivadas por ele. Conclusão: Verifica-se que a Educação Ambiental é uma estratégia viável para a Atenção Primária à Saúde que pode ter alcance comunitário e trabalhar questões socioambientais que interferem na condição de saúde das pessoas.

Keywords: Environmental Health Diagnosis of Health Situation in Specific Groups Disease Prevention

\section{Abstract}

Environmental education should not only discuss the physical environment, but also contextualise the local health care with emphasis on the disease prevention and management of environmental factors detrimental to health. Objective: This paper aims highlight the strategic importance of environmental education for the work in Primary Health Care in an isolated small urban center in the city of Uberaba. Method: Socio-environmental diagnosis was made in the period of August/2009 January/2010 through the application of semi-structured questionnaire for quantitative and qualitative research on health, environment and social development. Based on the results of the diagnosis, were prepared activities involving meetings, lectures and cultural events that discussed the problems in diagnosis. The assessment of efficacy was performed by verifying community action that arose after the activities. Results: Obtained the mobilization of the Municipal Health on the quality of drinking water and the community mobilization for organization and dealing with problems experienced related to education, health care and community representation. These actions are not due exclusively to the work carried out education, but were motivated and encouraged by it. Conclusion: It appears that environmental education is a viable strategy for Primary Health Care to may have community outreach and working environmental issues that affect the health status of people. 


\section{Palabras clave: Resumen}

Diagnóstico de la Situación de Salud en Grupos Específicos Prevención de Enfermedades
La educación ambiental no sólo se debe discutir el medio ambiente físico, sino también contextualizar los servicios locales de salud con énfasis en la prevención de enfermedades y manejo de los factores ambientales perjudiciales para la salud. Objetivo: El presente trabajo pretende estudiar la importancia estratégica de la educación ambiental para el trabajo en Atención Primaria de Salud en un pequeño centro urbano en la ciudad de Uberaba. Método: Se realizó diagnóstico socio-ambiental en el período de Agosto/2009 hasta Enero/2010 con la aplicación de cuestionario semi-estructurado para la investigación cuantitativa y cualitativa sobre la salud, el medio ambiente y el desarrollo social. Basándose en los resultados del diagnóstico, se prepararon actividades relacionadas con reuniones, conferencias y eventos culturales que se discutieron los problemas en el diagnóstico. La evaluación de la eficacia se realizó mediante la verificación de la acción comunitaria que surgió después de las actividades. Resultado: Se obtuvo la movilización de la Salud Municipal para mejora de la calidad del agua potable y tambien obtuvo la movilización de la comunidad para organización y tratamiento de los problemas experimentados en relación con educación, la salud y la representación social. Estas acciones no se deben exclusivamente a la labor llevada a cabo por la educación, pero estaban motivados y animados por la misma. Conclusión: Hay encontrado que la educación ambiental es una estrategia viable para la Atención Primaria de Salud que puede alcanzar a la comunidad y trabajar las cuestiones ambientales que afectan el estado de salud de las personas de las personas.

\section{Introdução}

A Educação Ambiental, para que cumpra seu papel, não deve discutir somente o meio ambiente físico, mas também abordar a realidade local e toda a complexidade das relaçôes entre meio ambiente e sociedade. Dessa forma, deve contextualizar a saúde local, destacando os cuidados com a prevenção de doenças e gestão dos fatores ambientais deletérios à saúde, tornando-se uma estratégia para a Atenção Primária.

Define-se atenção primária à saúde como o conjunto de açóes voltadas à prevenção de doenças e proteção da saúde; por isso, ocorre no período chamado pré-patogênico, antes da instalação da doença ${ }^{1}$.

Segundo Natal $(2004)^{1}$, a atenção primária pode ser focada em uma patologia em específico, ou ser mais genérica, abrangendo fatores determinantes de saúde como um todo.

Atuar preventivamente tem ganhos significativos e pode representar um avanço nos serviços de saúde. Por exemplo, o saneamento: diante dos agravos ocasionados pela falta de saneamento, realidade que ainda persiste no Brasil especialmente em áreas mais pobres, tem-se que, para cada $\mathrm{R} \$ 1,00$ (um real) investido em saneamento, economizam-se $\mathrm{R} \$ 4,00$ (quatro reais) em medicina curativa ${ }^{2}$.

Partindo do princípio de que o meio ambiente, em seus fatores físicos, químicos e biológicos, é fator determinante das condições de saúde, é de suma importância que estes sejam abordados pela Atenção Primária, na perspectiva do alcance da Saúde Ambiental.

Esse é um dos princípios da gestão em saúde no Brasil, e que levou à construção da proposta de Política de Saúde Ambiental.

Por essa proposta, faz-se a integração política entre meio ambiente e saúde, tendo por objetivo a proteção e a promoção da saúde humana e a colaboração na proteção do meio ambiente, por meio de açôes sobre os determinantes socioambientais e da prevençáo de agravos decorrentes da exposiçáo humana a ambientes diversos, sendo uma das principais linhas de atuação, a estruturação e fortalecimento da Vigilância em Saúde Ambiental ${ }^{3}$.

Pela Instrução Normativa no 1 , de 7 de março de 2005, a Vigilância em Saúde Ambiental compreende o conjunto de açóes e serviços sobre os fatores e condicionantes do meio ambiente que interferem na saúde, por meio da prevenção e do controle ${ }^{4}$. Ou seja, é um trabalho que se baseia na Atenção Primária a Saúde, aqui focada na Saúde Ambiental.

A Atenção Primária em Saúde Ambiental (APSA) se embasa no respeito ao setor de saúde como promotor do processo e recoloca a saúde ambiental como objeto agregador das açôes no nível local na construçáo de espaços, contextos e populaçôes saudáveis. Para isso, é necessária a integração entre órgãos de governo, sociedade civil organizada e demais profissionais, por meio do papel social que cada formação possui ${ }^{2}$.

Porém, segundo os mesmos autores, a atenção básica, através do Programa Saúde da Família (PSF), tem o desafio da aplicação da APSA. O programa tem avançado na melhoria do acesso das populaçóes à assistência médica, mas quanto às açôes sobre o meio ambiente, ainda necessita de formação específica, sendo grande a demanda da população por açóes voltadas ao monitoramento de fatores ambientais.

Por isso, é necessária a integração profissional, a participação e cogestáo do meio ambiente e da saúde, seja na gestáo pública ou não.

Um exemplo de trabalho voltado à atenção primária à saúde é o Projeto de Iniciação Científica desenvolvido por graduandos em Engenharia Ambiental e Terapia Ocupacional da Universidade de Uberaba (Uberaba, MG), intitulado: Equilíbrio socioambiental: práticas sustentáveis no Cerrado 
do Triângulo Mineiro. O projeto foi desenvolvido no Núcleo de Desenvolvimento Santa Fé, um pequeno núcleo urbano isolado no Município de Uberaba, distante $30 \mathrm{~km}$ da sede do município.

Este projeto teve por objetivo a intervenção em Educação Ambiental e Atenção Primária à Saúde na Comunidade Santa Fé, devido a sua localização distanciada dos bens e serviços comunitários urbanos disponíveis em Uberaba, MG. Os trabalhos pautaram-se na discussão dos problemas intrínsecos à realidade local da comunidade, com vistas à mobilização para a melhoria das condiçôes locais e da qualidade de vida dos moradores.

O trabalho de educação aplicado a comunidades envolve o diagnóstico socioambiental e de endemias, mobilização comunitária, planejamento, ação e análise crítica das atividades.

Santa Fé é uma comunidade fundada pelo Instituto Nacional de Colonização e Reforma Agrária - INCRA em 1990, como uma comunidade rural. Devido aos parcelamentos informais dos lotes em áreas menores que o permitido pelo INCRA, ocorreu a intervençáo do poder público municipal com o intuito de regularizar a ocupação, que definiu a comunidade como área urbana em 2006, passando a comunidade a fazer parte da área urbana de Uberaba por meio da Lei Complementar 359/2006 - Lei do Plano Diretor ${ }^{5}$ e da Lei Complementar No 374/2007 - Lei do Perímetro Urbano de Uberaba ${ }^{6}$.

No local, residem aproximadamente 200 famílias, sendo 130 na Zona Urbana do Núcleo e as demais na Zona de Amortecimento, entendida como área rural da Comunidade, conforme Figura 1.

As comunidades distanciadas dos serviços de assistência médica, educação, cultura e lazer são mais vulneráveis à ocorrência de problemas socioambientais, como a degradação do meio ambiente, a não valorização das características peculiares, e as condiçóes precárias de saúde ou acesso a ela, causando danos ao meio ambiente e à populaçáo como um todo. Por isso, a Comunidade Santa Fé foi escolhida para a realização do projeto, por caracterizar uma realidade microesférica do que atualmente têm-se conhecimento em âmbito global e por ter demonstrado interesse em realizar atividades propostas, ciente das suas necessidades sociais e ambientais.

A Educação Ambiental, segundo Pelicioni e Phillippi Junior $(2005)^{8}$, é a modalidade da educação voltada às questôes ambientais, não se podendo esquecer que essas questôes se enraízam em causas socioeconômicas, políticas e culturais, que também devem ser abordadas. Sendo assim, envolve conhecimentos diversos, como as bases da Educação, as Ciências Ambientais, as Ciências Sociais, a História e as Ciências da Saúde entre outros conhecimentos.
A Política Nacional de Educação Ambiental traz em seu artigo $2^{\circ}$ que

[...] a educação ambiental é um componente essencial e permanente da educação nacional, devendo estar presente, de forma articulada, em todos os níveis e modalidades do processo educativo, em caráter formal e não formal ${ }^{9}$.

Sendo assim, entendendo que o trabalho em atenção primária envolve práticas educativas voltadas à prevenção de doenças e promoção da saúde, a Educação Ambiental se torna ferramenta estratégica para a discussão socioambiental, na busca de alternativas para a resolução dos problemas vivenciados pela comunidade em questão, tanto orgânicos, quanto sociais e ambientais, podendo se desenvolver náo só no ambiente escolar, mas também em comunidades, aproveitando-se de conhecimentos locais.

Para Tassara e Ardans $(2005)^{10}$, educar pode ser entendido como a atuaçáo nos processos socializadores de indivíduos e grupos. Se o processo socializador trabalha aspectos socioambientais, pode ser entendido como educação ambiental. "Educar é ensinar a pensar"11.

A Educação Ambiental pode ser entendida como um processo que busca desenvolver consciência e preocupação com o meio e com os problemas existentes. As pessoas que participam são consideradas agentes de transformação social, envolvidos na melhoria da qualidade de vida, entendida como condição de bem-estar físico, psicológico e social em um ambiente equilibrado, que tenha requisitos básicos como suporte social; acesso a experiências, contatos e interaçóes; ambiente físico limpo e seguro; acesso a cultura e outros ${ }^{12}$.

Segundo Reigota (2009) ${ }^{13}$, um dos grandes méritos da questão ambiental é possibilitar análises e abordagens a diversas formaçôes. Por isso, a aplicação de conhecimento de diversas áreas dá caráter interdisciplinar à intervenção. Daí, a importância da participação de profissionais de diversas áreas nos trabalhos educacionais voltados à Atenção Primária.

O presente trabalho teve por objetivo estudar a importância da estratégia da Educação Ambiental para os trabalhos em Atençẫo Primaria à Saúde com base no projeto interdisciplinar desenvolvido em Santa Fé, em Uberaba, MG.

\section{Metodologia}

O projeto, aprovado pelo Comitê de Ética da Universidade de Uberaba em março de 2009, sob número de processo CAAE-0086.0.227.000-08, com duração de dois anos, teve início em agosto de 2009. 


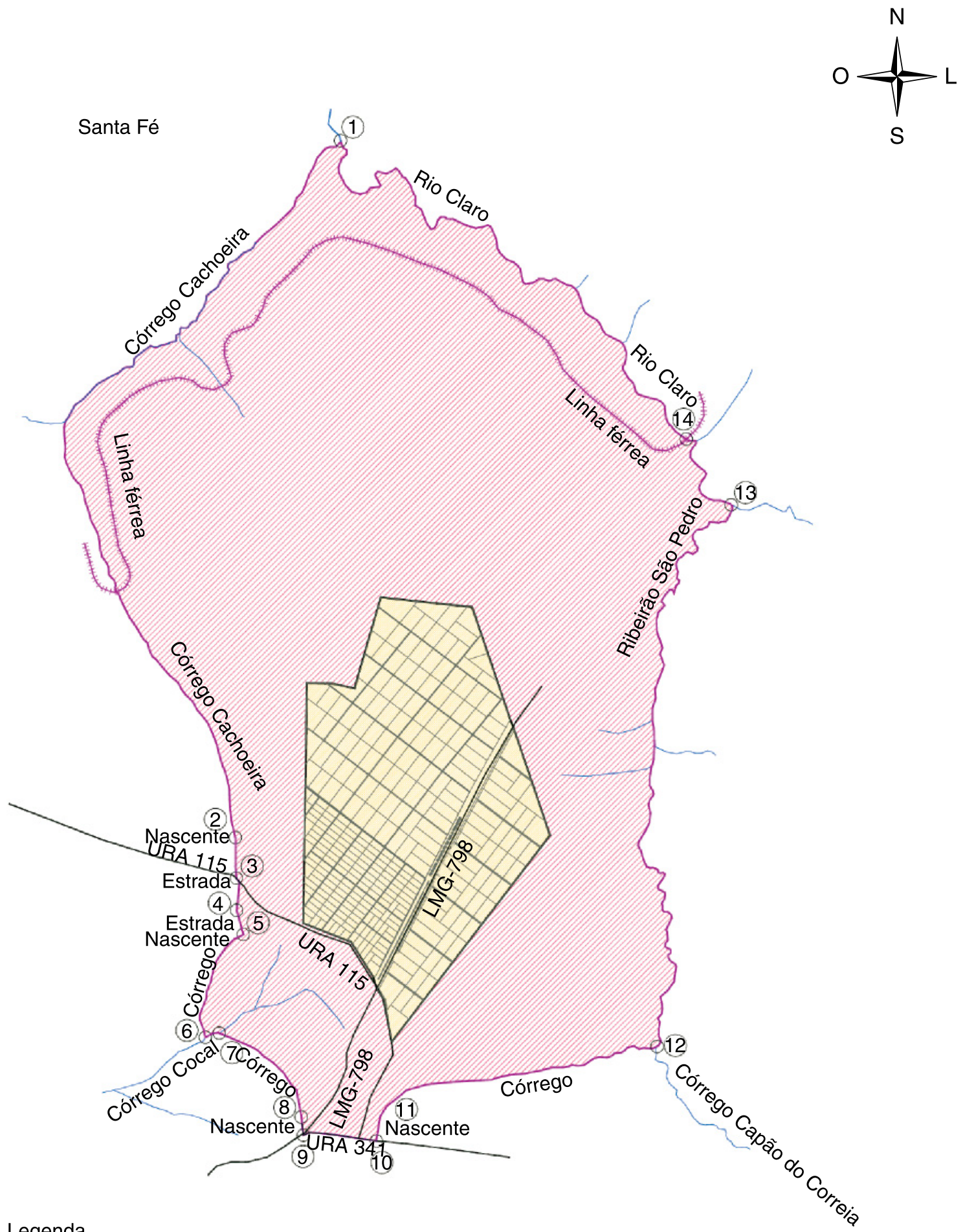

Legenda

Limite do perímetro urbano Limite da área de transição urbana

Limite da área urbana

Escala gráfica

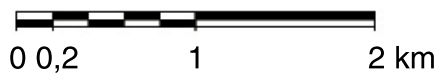

Figura 1. Zoneamento do núcleo Santa Fé. Fonte: Prefeitura Municipal de Uberaba/MG (2007a) 


\section{0 diagnóstico socioambiental da Comunidade Santa Fé}

Inicialmente, foi realizado diagnóstico socioambiental por meio da aplicação de questionário semiestruturado de pesquisa quantitativa e qualitativa, abordando os temas: saúde, educação, economia familiar, alimentação, meio ambiente e meio sociocultural, para melhor entendimento da dinâmica da comunidade e para estruturar as atividades de Atenção Primária à Saúde e Educação Ambiental com base em seus resultados.

Para aplicação do questionário, foram realizadas visitas domiciliares no período de 15 de agosto de 2009 a 19 de janeiro de 2010.

$\mathrm{O}$ instrumento foi composto de quarenta e uma questôes para verificação, dentre outros aspectos, do grau de escolaridade e acesso à educação, da composição da renda familiar, da mobilidade e os meios de transporte utilizados, das relaçóes sociais, do uso dos recursos ambientais, da assistência e apoio recebidos nas atividades desenvolvidas e da satisfaçáo das pessoas e perspectivas de mudanças.

O espaço amostral para a aplicação do questionário foi a área urbana do Núcleo, sendo entrevistadas 101 das 130 famílias (78\%) que lá residem. As demais famílias não foram entrevistadas por não aceitarem responder ao questionário ou por não haver, no período de realizaçáo das entrevistas, nenhuma pessoa em casa. As famílias residentes na área rural do núcleo não foram entrevistadas devido à distância de suas casas da área urbana do núcleo e devido a restriçóes de transporte por parte da equipe de pesquisadores.

Para a realização das entrevistas, foi assinado termo de consentimento pelos participantes, assegurando-se o caráter confidencial das informaçōes prestadas.

Os dados coletados nas entrevistas foram organizados em tabelas para facilitar a análise de cada uma das questóes e a composição de dados estatísticos, utilizando método de contagem e construção de gráficos.

Para as questóes abertas, optou-se por anotar as respostas, preservando ao máximo a ênfase e a colocação das palavras e termos utilizados. A tabulação desses dados foi feita por meio do agrupamento das ideias afins, conforme os objetivos e pontos analisados em cada questáo.

\section{Atividades de conscientização e mobilização comunitária}

Ainda durante a fase de diagnóstico, foi realizada a mobilização da comunidade e a exposição dos objetivos do projeto, por meio de eventos sociais e atividades artísticas, como a comemoração do dia das crianças com teatro sobre valores, meio ambiente e saúde; o Espaço Saúde, no qual foram desenvolvidas oficinas diversas voltadas à qualidade de vida como aferição de pressão e medição de glicemia, alongamento e automassagem, nutrição, doenças sexualmente transmissíveis, medição e pesagem de crianças, artesanato e confecção de brinquedos, corte de cabelo e teatro sobre meio ambiente; e a comemoração do Natal.

Com base nos resultados do diagnóstico, foram elaboradas atividades de Educação Ambiental que envolveram reunióes, análise da qualidade microbiológica da água de consumo humano, palestras e eventos culturais voltados à discussão dos problemas verificados no diagnóstico.

As reuniôes foram realizadas tanto com a comunidade como um todo quanto somente com os líderes comunitários. As reuniōes comunitárias visavam à apresentação das atividades propostas e à mobilização para a participação. As reunióes com os líderes visavam reforçar o papel das lideranças na disseminação dos objetivos e diminuir atritos e divergência de intençôes entre eles.

Eventos como o Circuito Tela Verde, organizado pelo Ministério do Meio Ambiente, foram realizados para a discussão em Educação Ambiental e Atenção Primária à Saúde. O evento consistiu na apresentação de curtas-metragens disponibilizados pelo Ministério do Meio Ambiente sobre temas ligados aos problemas ambientais, como conservaçáo da água, geração de resíduos, vivência comunitária e conservação de Biomas.

As reunióes comunitárias e os eventos realizados eram abertos a todos os membros da comunidade, sem distinção de sexo ou idade. A participaçáo das pessoas foi assegurada pela assinatura em termo de consentimento. Pela participaçáo, não houve custos ou pagamento de qualquer natureza aos participantes, sendo a mesma voluntária.

\section{Verificação da qualidade da água de consumo humano}

Para verificar a qualidade da água de consumo humano, foram realizadas análises microbiológicas de 30 amostras coletadas nos dias 13 e 14 de Abril de 2010. A Comunidade é composta por quatro glebas, chamadas de Santa Fé I, II, III e IV. Para estipular a quantidade de amostras a serem coletadas por gleba, o critério utilizado, além da extensão geográfica, foi o de adensamento populacional, já que na Comunidade existem áreas extensas, porém pouco ocupadas, e áreas menores com maior número de domicílios.

Depois de estipulada a quantidade de amostras por gleba, os pontos foram escolhidos aleatoriamente. Na Figura 2, 


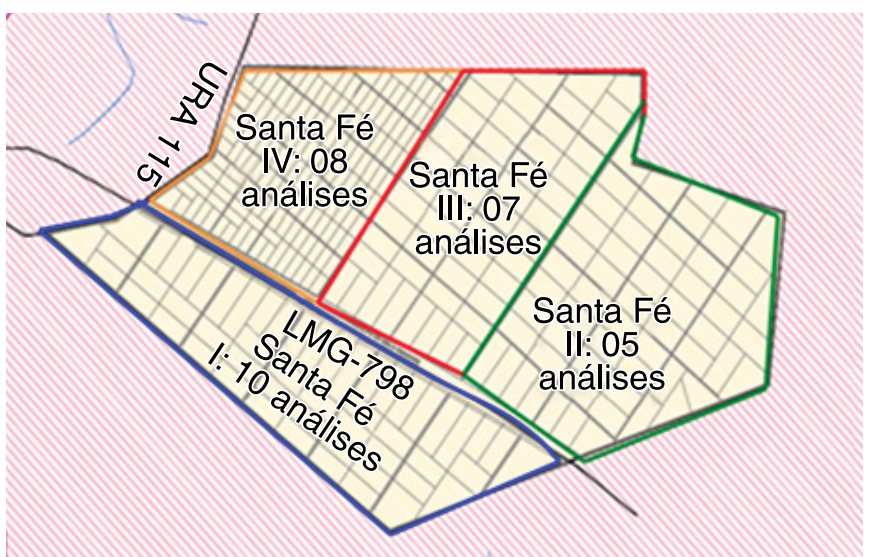

Figura 2. Amostras coletadas por área da Comunidade. Fonte: Adaptado da Prefeitura Municipal de Uberaba (2007a) ${ }^{7}$.

verifica-se a quantidade de amostras coletadas por área da Comunidade.

Para a coleta de amostras de água, preparou-se um documento que foi utilizado como termo de consentimento. Nele continha a identificação da coleta, forma de captaçáo da água, tratamento realizado antes do consumo e ponto de coleta, além da assinatura do responsável autorizando a coleta da amostra, a análise e a utilização dos resultados na garantia da não identificação dos sujeitos envolvidos.

Os procedimentos de análise foram realizados no laboratório de Microbiologia da Universidade de Uberaba. Utilizaram-se as técnicas dos tubos múltiplos para contagem de coliformes fecais a $35^{\circ} \mathrm{C}$ e a $45^{\circ} \mathrm{C}$, e a Contagem Padrão em Placa pela técnica de semeadura Pour Plate.

Os resultados das análises foram tabelados para análise estatística e, com base nos parâmetros estabelecidos pela Portaria 518 do Ministério da Saúde ${ }^{14}$, a água de cada domicílio foi classificada como própria ou imprópria para consumo. Foram consideradas próprias para consumo as amostras que apresentaram número mais provável de coliformes fecais menor ou igual a $5 \times 10^{2}$ e 3 ou menos unidades formadoras de colônias de bactérias.

Durante o mês de julho de 2010, os domicílios em que ocorreu coleta de amostras foram visitados para a entrega e discussão dos resultados. Foi realizado trabalho de conscientização voltado à comunidade como um todo quanto aos cuidados com a água de consumo humano.

As atividades realizadas no projeto tiveram a eficácia avaliada por meio da verificação de ações e mudanças comunitárias que surgiram após os trabalhos de conscientização. Essa fase ocorreu entre os meses de dezembro de 2010 e maio de 2011.

\section{Resultados e discussão}

\section{Os resultados do diagnóstico}

Por meio do diagnóstico realizado, verificou-se que na Comunidade náo existe rede de água tratada nem rede de coleta de esgoto. A água de consumo humano é retirada de poços artesianos ou cisternas individuais, sendo que 53\% das famílias a consomem sem nenhum tipo de tratamento, conforme Figura 3.

Do total de famílias, 94\% utilizam fossa negra para depósito dos esgotos domésticos, $14 \%$ têm esgoto a céu aberto e apenas $4 \%$ possuem fossa séptica.

Com relação aos resíduos, somente $12 \%$ das famílias afirmaram ser atendidas pelo caminhão de coleta; $51 \%$ delas os queimam; $20 \%$ depositam-nos em terrenos baldios; $8 \%$ os enterram; e $48 \%$ depositam os resíduos em caçambas localizadas à beira da Rodovia.

Concomitantemente à ocorrência desses fatores, foram relatados quatro casos de hepatite e domicílios com quadros frequentes de diarreia que podem estar relacionadas à ingestáo de água imprópria ao consumo. Há relatos de acometimento por outras doenças como dengue, malária e hantavírus que, segundo o Instituto Mineiro de Gestão das Águas - IGAM (2008) $)^{15}$, também são de veiculação hídrica. Foram relatados cinco casos de dengue, um de malária e um de hantavírus.

A carência de níveis adequados de sanidade ambiental na Comunidade contribui para a ocorrência de animais que podem ser vetores de doenças, tais como ratos silvestres, ratazanas, carrapatos e baratas, cuja presença foi relatada por 43\% dos entrevistados.

Quanto às análises microbiológicas da água realizadas, verificou-se que 13 das 30 amostras (43\%), apresentaram-se impróprias para o consumo humano, de acordo com os padróes estabelecidos. Na Tabela 1, pode ser verificado o resultado das análises.

Dos 30 domicílios, 53\% consumiam água sem nenhuma forma de tratamento.

Quanto à ocorrência de morbidades, foi relatada, durante as entrevistas, a ocorrência de doenças causadas por fatores genéticos, etários ou relacionados a hábitos do dia a dia, conforme pode ser visualizado na Tabela 2 .

Dos domicílios visitados, $53 \%$ possuem pelo menos um membro que é fumante e em $33 \%$ há pelo menos um membro que faz uso contínuo do álcool. 


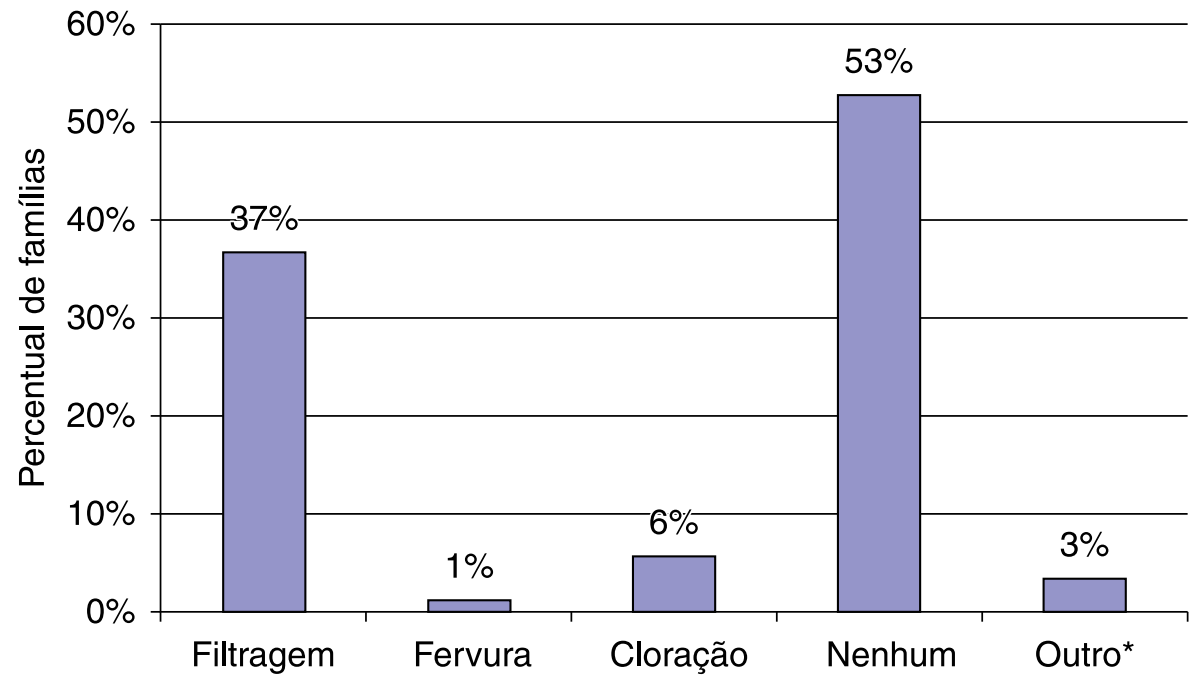

Figura 3. Formas de tratamento da água antes do consumo na comunidade Santa Fé. *Calcário virgem, leva de Uberaba.

Tabela 1. Resultado das análises microbiológicas da água de consumo humano em Santa Fé.

\begin{tabular}{|c|c|c|c|c|c|c|c|}
\hline \multicolumn{4}{|c|}{ Análise de água } & \multicolumn{4}{|c|}{ Análise de água } \\
\hline Amostras & PCA & LST & Condição da água & Amostras & PCA & LST & Condição da água \\
\hline 1 & $3,4 \times 10^{2}$ & 3,6 & Imprópria & 16 & $4,6 \times 10^{3}$ & $<3,0$ & Imprópria \\
\hline 2 & $2,0 \times 10^{2}$ & $<3,0$ & Própria & 17 & $3,0 \times 10^{2}$ & $<3,0$ & Própria \\
\hline 3 & $<10$ & $<3,0$ & Própria & 18 & $1,0 \times 10^{2}$ & $<3,0$ & Própria \\
\hline 4 & $2,0 \times 10^{2}$ & $<3,0$ & Própria & 19 & $3,0 \times 10^{3}$ & $<3,0$ & Imprópria \\
\hline 5 & $1,0 \times 10^{2}$ & $<3,0$ & Própria & 20 & $1,5 \times 10^{2}$ & $<3,0$ & Própria \\
\hline 6 & $1,2 \times 10^{5}$ & $260(4)$ & Imprópria & 21 & $7,3 \times 10^{3}$ & $<3,0$ & Imprópria \\
\hline 7 & $2,0 \times 10^{2}$ & $<3,0$ & Própria & 22 & $9,6 \times 10^{3}$ & $<3,0$ & Imprópria \\
\hline 8 & $1,1 \times 10^{2}$ & $<3,0$ & Própria & 23 & $4,7 \times 10^{3}$ & $<3,0$ & Imprópria \\
\hline 9 & $3,0 \times 10$ & $<3,0$ & Própria & 24 & $1,3 \times 10^{3}$ & $<3,0$ & Imprópria \\
\hline 10 & $4,0 \times 10$ & $<3,0$ & Própria & 25 & $1,7 \times 10^{4}$ & 6,9 & Imprópria \\
\hline 11 & $3,0 \times 10^{3}$ & 3,6 & Imprópria & 26 & $8,0 \times 10^{2}$ & $<3,0$ & Própria \\
\hline 12 & $1,2 \times 10^{3}$ & $<3,0$ & Imprópria & 27 & 10 & $<3,0$ & Própria \\
\hline 13 & $9,0 \times 10^{2}$ & $<3,0$ & Imprópria & 28 & 10 & $<3,0$ & Própria \\
\hline 14 & $2,0 \times 10^{2}$ & 3,6 & Imprópria & 29 & $2,6 \times 10^{4}$ & $<3,0$ & Imprópria \\
\hline 15 & $6,0 \times 10$ & $<3,0$ & Própria & 30 & $7,0 \times 10^{2}$ & $<3,0$ & Própria \\
\hline
\end{tabular}

Padrão PCA (número mais provável de coliformes fecais)

Padrão LST (unidades formadoras de colônia) $5,0 \times 10^{2}$ ausência $(<3,0)$

Fonte: Acervo dos autores (2011).

A ocorrência desses fatores evidenciou a necessidade do trabalho de Atenção Primária à Saúde, por meio da educação ambiental e em saúde junto à comunidade.

\section{As atividades realizadas}

Para o trabalho em atenção primária, utilizou-se a estratégia da Educação Ambiental, tendo em vista que, segundo Pelicioni $(2005)^{16}$, grande parte dos agravos em saúde se relaciona com problemas ambientais, uma vez que as alterações no meio ambiente interferem na saúde e qualidade de vida das pessoas, de forma que meio ambiente e saúde são indissociáveis.

Das reuniôes comunitárias, resultou a criação do vínculo e a mobilização para a busca de soluçóes para os problemas vivenciados. Um exemplo é a regularização dos lotes da comunidade.

Das reuniôes com os líderes comunitários, resultou a mobilização para a formaçáo da Associação de Moradores. Até então, havia somente a Associação dos Produtores Rurais da Comunidade, cujo foco era a gestão das atividades rurais 
Tabela 2. Principais intercorrências em saúde na Comunidade Santa Fé.

\begin{tabular}{lc}
\hline \multicolumn{1}{c}{ Problema de saúde } & Prevalência por família (\%) \\
\hline A.V.C. & 4 \\
Artrite/Artrose & 14 \\
Câncer/Tumores & 9 \\
Depressão & 22 \\
Diabetes & 12 \\
Osteoporose & 8 \\
Distúrbio de memória & 10 \\
Problemas de coluna & 32 \\
Distúrbios de visão & 20 \\
Doenças cardiovasculares & 19 \\
Dores de cabeça & 11 \\
Hipertensão & 46 \\
DSTs & 2 \\
Obesidade & 4 \\
Transtornos respiratórios & 15 \\
Transtornos de humor & 11 \\
\hline
\end{tabular}

Fonte: Acervo dos autores (2010).

desenvolvidas no local. A Associação de Moradores, em parceria com a Associação de Produtores, poderá gerir as questóes afetas a infraestrutura urbana e serviços comunitários locais.

Os eventos realizados possibilitaram a abordagem de problemas específicos da comunidade por meio de linguagem e materiais adequados ao seu cotidiano.

O Espaço Saúde levou à preocupação com o cuidado pessoal e promoçáo da qualidade de vida.

A Festa do Milho levou à valorização da produção agrícola local. A produção de "chup-chup" com frutos do Cerrado (Bioma local) levou ao conhecimento do valor nutricional e cultural das frutas desse Bioma, pouco apreciadas pela população local.

A 2a Mostra Nacional de Produção Audiovisual Independente - Circuito Tela Verde, proposta veiculada pelo Ministério do Meio Ambiente como estratégia de alcance comunitário de discussão de problemas socioambientais, utilizando a metodologia da educomunicação, da qual participaram 301 espaços exibidores em nível nacional, levou à discussão do meio ambiente como fator determinante das condiçôes de saúde, entendendo que a saúde depende de um meio equilibrado e salubre. Em Santa Fé, a mostra foi realizada no dia 31 de Julho de 2010 . Os recursos audiovisuais atendem aos objetivos do trabalho em comunidades, fortalecendo a participação e proporcionando o entendimento das responsabilidades e dos valores existentes no meio social.

Os eventos de comemoração de datas festivas, como o Dia da Criança e o Natal, serviram para o fortalecimento do vínculo entre comunidade e pesquisadores, a partir do conhecimento das pessoas, das propostas e intençóes. Sem o vínculo, que demonstra a confiança na integridade da proposta do outro, não é possível o aprofundamento a ponto de alcançar as raízes dos problemas, nem tampouco alcançar a participação popular.

Utilizou-se da arte na forma de teatro, caracterização de personagens, música e dança. O uso de recursos artísticos, através da sensibilização quanto aos assuntos abordados nas açóes educativas, leva ao melhor envolvimento das pessoas nos eventos realizados, entendendo-as como um "corpo sonhador", que cria novos entendimentos sobre a vida, novas percepçóes de mundo, novos desejos no e para o corpo, ou seja, novas subjetividades ${ }^{17}$.

$\mathrm{O}$ artesanato foi uma estratégia que serviu para fortalecer habilidades, formar grupos e valorizar a cultura e materiais locais. Por meio dessa atividade, abordou-se o meio ambiente cultural, de suma importância para a manutenção da saúde e da qualidade de vida. Entende-se a cultura como um modelador ambiental e condicionador da saúde.

Segundo Montagu (1972, p. 131) ${ }^{18}$,

[...] a cultura é a criação conjunta do indivíduo e da sociedade, que interagem mútua e reciprocamente, para se servirem, manterem, sustentarem e desenvolverem um ao outro.

De posse dos resultados das análises de qualidade da água, promoveu-se a orientação das famílias que tiveram a água analisada e foi realizada palestra sobre o tema para toda a comunidade, com distribuição de panfletos informativos sobre cuidados com a água de consumo humano e limpeza de caixa d'água. Essa é uma estratégia de prevenção de doenças de veiculação hídrica, já reladas pela comunidade.

Por meio dos trabalhos realizados, obtiveram-se: a) a mobilização comunitária para a resolução de seus próprios problemas, como a regularização dos lotes, pendente desde a fundação da comunidade; b) reuniōes entre representantes da comunidade e lideranças políticas acerca dos problemas da comunidade como policiamento, educação e saúde; c) a mobilizaçáo comunitária para a estruturação da Associação de Moradores; d) o desenvolvimento de atividades comerciais como o bazar e comercialização de chup-chup; e) e mobilização comunitária para a implantaçáo de posto policial. Essas ações não se devem exclusivamente ao trabalho de educação realizado, mas foram motivadas e incentivadas por ele.

O Conselho Municipal de Saúde, de posse dos dados obtidos no projeto, articulou o monitoramento da qualidade da água da creche comunitária, sendo que o relatório de inspeçáo prevê a extensáo do monitoramento às residências da comunidade.

Por meio do projeto, conseguiu-se ainda a doação à comunidade da área física na qual serão disponibilizados 
serviços comunitários como posto de saúde e escola (ensino fundamental), o que representa um avanço para a comunidade que não dispunha, em todo o seu território, de áreas públicas para a efetivação desses serviços.

Será implantado em Santa Fé o Centro Municipal de Apoio e Recuperação ao Usuário de Crack e Outras (CAPS-AD), unidade que será referência no atendimento especializado à dependência química.

\section{Conclusão}

Verifica-se que a Educação Ambiental é uma estratégia viável para a Atenção Primária à Saúde que pode ter alcance comunitário e trabalhar questôes socioambientais que interferem na condição de saúde das pessoas, configurando-se num trabalho de prevenção de doenças e promoção da saúde.

Ressalta-se a importância da interdisciplinaridade e da participaçáo popular para o sucesso do trabalho em comunidade. O trabalho foi organizado por acadêmicos, mas foram as parcerias efetivadas, somadas à participaçáo da comunidade que levaram ao alcance desses resultados.

Quebrar a barreira do individualismo, na busca de objetivos comuns é a proposta da educação, fazendo surgir na comunidade açóes de enfoque coletivo.

O trabalho da educação não indica a solução, mas sim envolve a comunidade em uma atmosfera questionadora e reflexiva através da conscientização e da mobilização dos agentes sociais. As soluçóes devem nascer na comunidade, baseadas em suas próprias perspectivas, pois lá estão os sujeitos e as ferramentas necessárias à mudança.

Por meio desse trabalho, espera-se evidenciar o papel que a Educação Ambiental pode desempenhar em comunidades, como estratégia da Atenção Primária à Saúde e destacar o papel social que todas as formaçóes devem assumir na realização de suas atividades.

\section{Referências}

1. Natal D. Fundamentos de Saúde Pública. In: Philippi Junior A, Roméro MA, Bruna GC, editores. Curso de Gestão Ambiental. Barueri: Manole; 2004. cap. 9, p. 333-374. (Coleção Ambiental, n. 1).

2. Camello TCF, Garcia VS, Araujo SB; Almeida JR. Gestão e Vigilância em Saúde Ambiental. Rio de janeiro: Thex; 2009. 324 p.

3. Brasil. Ministério da Saúde. Conselho Nacional de Saúde. Subsídios para construção da Política Nacional de Saúde Ambiental. Brasília: Editora do Ministério da Saúde; 2007. 56 p. (Série B. Textos Básicos de Saúde). [acesso 2010 out. 26]. Disponível em: http://portal.saude. gov.br/saude/

4. Brasil. Secretaria de Vigilância em Saúde. Instrução Normativa $n^{\circ} 1$, de 07 de março de 2005. Dispõe sobre Vigilância em Saúde Ambiental. Diário Oficial da República Federativa do Brasil, Brasília, DF, 22 mar. 2005. [acesso 2010 out. 26]. Disponível em: http://portal.saude. gov.br/portal/arquivos/pdf/inst_normativa_01_2005.pdf

5. Uberaba. Prefeitura Municipal de Uberaba. Secretaria de Planejamento. Lei Complementar n 359, de 11 de outubro de 2006. Lei do Plano Diretor. Diário Oficial do Município de Uberaba, Uberaba, MG, out 2006. [acesso 2010 mar. 30]. Disponível em: http://www.uberaba.mg.gov.br

6. Uberaba. Prefeitura Municipal de Uberaba. Secretaria de Planejamento. Lei Complementar no 374, de 13 de junho de 2007. Lei do Perímetro Urbano Uberaba. Diário Oficial do Município de Uberaba, Uberaba, MG, jun. 2007. [acesso 2010 mar. 30]. Disponível em: http://www. uberaba.mg.gov.br

7. Uberaba. Prefeitura Municipal de Uberaba. Secretaria de Planejamento. Contém mapas do Plano Diretor. 2007. [acesso 2010 mar. 30]. Disponível em: http://www.uberaba.mg.gov.br

8. Pelicioni MCF, Philippi Junior A. Bases políticas, conceituais, filosóficas e ideológicas da educação ambiental. In: Philippi Junior A, Pelicioni MCF, editores. Educação Ambiental e Sustentabilidade. Barueri: Manole, 2005. cap. 1, p. 03-12. ISBN 85-204-2207-1. (Coleção Ambiental; 3)

9. Brasil. Presidência da República. Lei n 009795, de 27 de abril de 1999. Dispõe sobre a educação ambiental, institui a Política Nacional de Educação Ambiental e dá outras providências. In:Brasil. Presidência da República. Legislação de Direito Ambiental. São Paulo: Saraiva; 2008. 872 p. (Coleção Saraiva de Legislação).

10. Tassara ETO, Ardans O. Intervenção psicossocial: desvendando o sujeito histórico e desvelando os fundamentos da educação ambiental crítica. In: Ferraro Júnior LA, organizador. Encontros e Caminhos: formação de educadoras (es) ambientais e coletivos educadores. Brasília: Ministério do Meio Ambiente; 2005. v. 1, p. 201-216.

11. Alves R. Educação do olhar. Pais \& Filhos. [acesso 2011 fev. 15]. Disponível em: http://www.paisefilhos.pt/ index.php/opiniao/rubemalves/2324-educacao-do-olhar

12. Mazzini ALDA. Dicionário Educativo de Termos Ambientais. 2. ed. Belo Horizonte: Mazzini; 2003. 384 p.

13. Reigota M. Prefácio. In: Gómez JAD, Aguado OV, Pérez AG, organizadores. Serviço Social e meio ambiente. 3. ed. Tradução de Silvana Cobucci Leite; Revisão técnica de Marcos Reigota. São Paulo: Cortez; 2009. p. 07-10. Título original: Trabajo social y medio ambiente.

14. Brasil. Ministério da Saúde. Portaria n 518, de 25 de março de 2004 Estabelece os procedimentos e responsabilidades relativos ao controle e vigilância da qualidade da água. Diário Oficial da República Federativa do Brasil, Brasília, DF, 26 mar. 2004. [acesso 2010 out. 26]. Disponível em: http://portal2.saude.gov.br/saudelegis/LEG_norma_ pesq_consulta.CFM

15. Minas Gerais. Instituto Mineiro de Gestão das Águas - Igam. Glossário de Termos: gestão de recursos hídricos e meio ambiente. Belo Horizonte: Igam; 2008. 90 p.

16. Pelicioni MCF. Promoção da saúde e meio ambiente: uma trajetória técnico-política. In: Philippi Junior A, Pelicioni MCF, editores. Educação Ambiental e Sustentabilidade. Barueri: Manole; 2005. cap. 16, p. 413-420. (Coleção Ambiental, n. 3).

17. Almeida MVM. Corpo e Arte em Terapia Ocupacional. Rio de Janeiro: Enelivros; 2004.

18. Montagu A. Introdução à antropologia. São Paulo: Cultrix; 1972. 268 p. 